\title{
Numerical characterization of vermiculite-concrete mixture used as a shock absorber for a nuclear waste container
}

\author{
N. Zaccari, M. Torrigiani \& G. Forasassi \\ Dipartimento di Ingegneria Meccanica, Nucleare e della Produzione, \\ University of Pisa, Italy
}

\begin{abstract}
This paper deals with numerical and experimental analyses of a type $B(U)$ package for radioactive waste transport. $9 \mathrm{~m}$ vertical free drop tests, performed on reduced scale models, are described and analysed. The experimental results are compared with numerical simulations performed with FEM computer codes, considering reduced scale models as well as the prototype. Firstly the paper deals with the numerical characterization of vermiculite-concrete mixture used as a shock absorber in this kind of package by considering the literature data and the experimental test performed at Pisa University. Moreover, the paper shows the results of a similitude analysis which permits one to extrapolate the data obtained by means of the reduced scale models to the prototype. Small errors were obtained considering models of large scale $(1: 2,5)$ and medium scale $(1: 4)$ in comparison with the smaller scale results.
\end{abstract}

Keywords: vermiculite, shock absorber, dimensional analysis, packaging, radioactive waste.

\section{Introduction}

Radioactive wastes are shipped in casks designed to prevent the release of the radioactive material to the environment in normal as well as accidental conditions. The latter are established by the relevant rules (IAEA Recommendations) by means of a series of experimental tests. In Italy ENEA has studied for many years, in collaboration with University of Pisa, several containers and packages to collect many types of radioactive sources of different radionuclides no longer used in hospitals around the country. To improve the 
storage of those sources, from the safety point of view, and to ease this transport, it has been planned to design a Type $\mathrm{B}(\mathrm{U})$ package on the base of the experience gained in the past with the other Type $\mathrm{B}(\mathrm{U})$ packages (CF6 and CF66). The energy absorption in CF6 and CF66 packages is due mainly to VermiculiteConcrete mixture used as a shock absorber and thermal insulator. In this paper the numerical characterization of this material, by means of a finite element approach, is discussed. The work's objective was to assess the numerical model and the parameters used in the material model to simulate the dynamic impacts of packages. The experimental drop tests on the scaled cask containers filled with vermiculite-concrete mixture, made at University of Pisa in the 1980s, were taken into account for the model validation. Moreover, the paper shows the results of a similitude analysis which permits one to extrapolate the data obtained by means of the reduced scale models to the prototype. Finally, the prototype behaviour in vertical drop tests according to the IAEA rules [3] was simulated. The results obtained by the comparison between experimental and numerical results are quite satisfactory in terms of acceleration and deformations.

\section{Mechanical characteristics of vermiculite-concrete mixture}

A material which is suitable for use as a shock mitigator, or shock isolator, must have certain specific basic properties. It must limit the force transmitted through it to some predetermined value which is essentially independent of the deformation which the material undergoes, even though this deformation is extremely large. This limiting force should also be basically independent of the rate of deformation. Concrete made of vermiculite, water and containing large amounts of air appear to have many of these desirable properties. In the case of radioactive waste package, the air and water are, also, essential to protect the internal cask from fire in standard blaze accident conditions.

In this section the main characteristics of a vermiculite-concrete mixture deduced from the literature [1] are reported. In Figure 1 are shown the static and dynamic stress-strain curves for a mixture of vermiculite-concrete with the indicated characteristics. The vermiculite is a micaceous mineral that exfoliates when heated or subjected to certain chemical reactions. It is a hydrated magnesium-aluminum-iron silicate. The vermiculite aggregate has a density of 112 to $160 \mathrm{Kg} / \mathrm{m}^{3}$ [1]. The cement used was a Portland Cement. The lightweight concrete used in the investigation [1] was prepared at the University of Texas [1]. All the concrete was proportioned with a water to cement to vermiculite volume ratio of $3.08: 1: 8$. The concrete was mixed in batches of $0.28 \mathrm{~m}^{3}$ of vermiculite, $0.007 \mathrm{~m}^{3}$ of cement, and $2.2 \mathrm{~m}^{3}$ of water to which $100 \mathrm{gm}$ of a neutralized vinsol resin admixture was added to make an easily workable mixture. Finally a 20-30 \% of air was brought in. All the dynamic stress-strain and static stress-strain measurements were made with the specimens confined laterally. When prepared for a test, the specimens were confined in long steel pipes (see fig. 1) with a thin wall. An aluminum plate $13 \mathrm{~mm}$ thick was placed on top of the specimen, and a steel pipe was placed on top of the plate [1]. The static 
stress-strain curve of Figure 1 provides the following information concerning the mixture:

1. The first part is a elastic part with Young modulus equal to about $144 \mathrm{MPa}$. This part corresponds to the elastic part of the concrete structure that represents a rigid structure inside the mixture.

2. The yield strength is the maximum stress allowed from the concrete before the collapse. This value, for this kind of mixture, is equal to 1.25 MPa.

3. After the concrete structure collapse, the mixture presents a hardening phase.

The maximum stress reached at $40 \%$ of deformation is equal to $3.5 \mathrm{MPa}$.

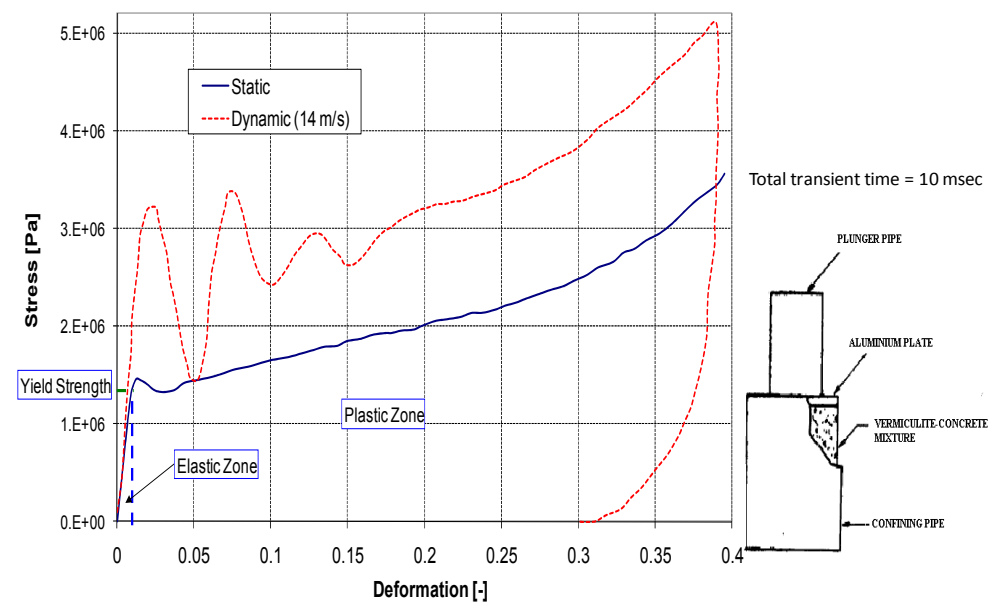

Figure 1: Static and dynamic stress-strain curve of Vermiculite-concrete mixture.

From a dynamic point of view, Figure 1 demonstrates that the yield stress of the mixture increases with the strain-rate. This effect is well known also in metals and it is implemented in a FE code with a Cowper-Symonds model (see section 5). The energy dissipated by a material depends upon two factors: (1) the deformation of the material, and (2) the forces in the mixture during the deformation. The amount of energy absorbed is the product of the average force and the deformation. The area under the force-displacement curve is equal to the dissipated energy. This data was used as a first tentative approach to reproduce the experimental results in the considered application.

\section{Vertical drop tests on the CF packages}

The experimental tests, made at Pisa University in 1980 [2], involved two kinds of waste packages, the CF-6 and the CF-66 package. In Figure 2 is shown the CF-6 package with the main dimensions. The CF-66 package has the same geometry but it is 1.6 times greater than CF-6. The CF-6 package is a scale model (1:4) of a Prototype waste container under development at University of 
Pisa in collaboration with ENEA. The aim of this investigation was to demonstrate the negligible scale effect on this package to develop the 1:1 scale package and to verify the absorbing capacity of vermiculite-concrete mixture. The reduced scale models are very interesting from economics and practical points of view. In fact the knowledge of scale laws allows one to make some tests on the scale model with an enormous economic saving.
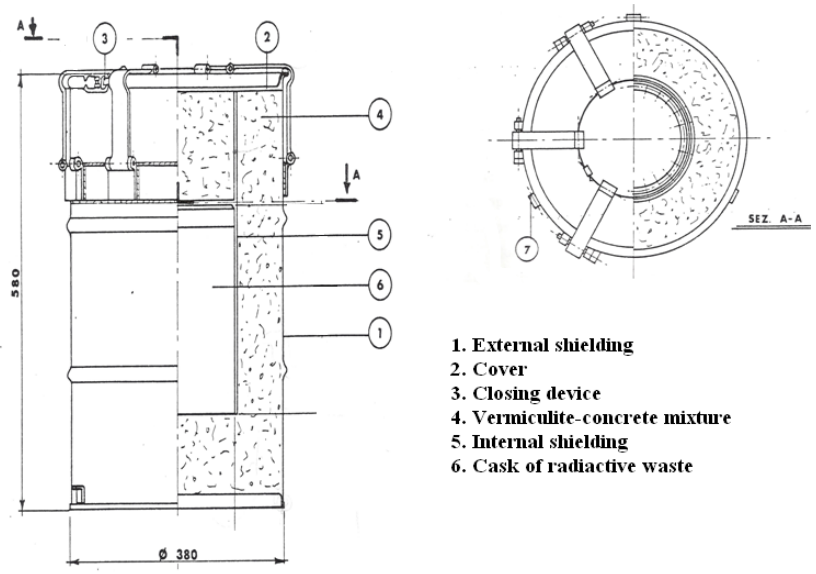

1. External shielding

2. Cover

3. Closing device

4. Vermiculite-concrete mixture

5. Internal shielding

6. Cask of radiactive waste

Figure 2: CF6 package: main dimensions.

In this paper we have consider only the vertical drop tests on the CF packages. The vermiculite-concrete mixture used in the CF packages was similar at the mixture the seen in section 1 but with different proportions between waterconcrete-vermiculite. The main characteristics of material used in CF packages are shown in Table 1. In Figures 3 and 4 are shown the average results of several vertical drop tests in terms of accelerations, velocity and displacements.

Table 1: $\quad$ Main characteristics of the shock absorber and shielding materials.

\begin{tabular}{|c|c|c|c|c|}
\hline $\begin{array}{c}\text { Scale } \\
\text { model }\end{array}$ & $\begin{array}{c}\text { Shielding } \\
\text { Material }\end{array}$ & $\begin{array}{c}\text { Diameter } \\
(\mathbf{m m})\end{array}$ & $\begin{array}{c}\text { Height } \\
\mathbf{( m m})\end{array}$ & $\begin{array}{c}\text { Weight } \\
\mathbf{( K g )}\end{array}$ \\
\hline CF6 & ASTM 351 & 380 & 580 & 100 \\
\hline CF66 & ASTM 351 & 570 & 932 & 400 \\
\hline
\end{tabular}

\section{Similitude analysis}

The acceleration, a, transmitted by the shock absorber to the cask body can be considered a function of 8 variables:

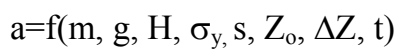

where this function can be written as follows: $F\left(a, m, g, H, \sigma_{y}, s, Z_{o}, \Delta Z, t\right)=0$ [4]. 

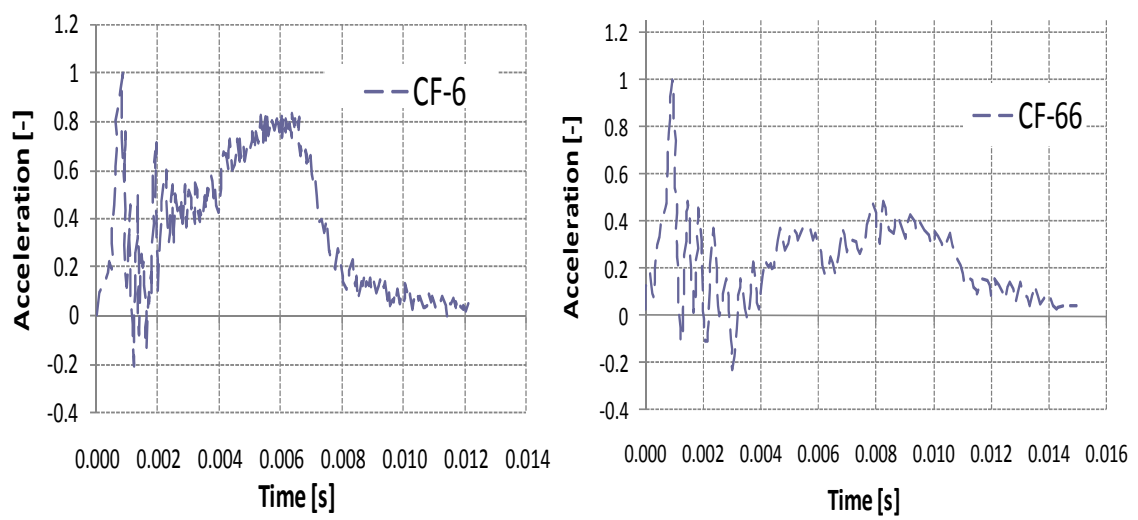

Figure 3: $\quad$ Experimental acceleration time history of CF6 and CF66.
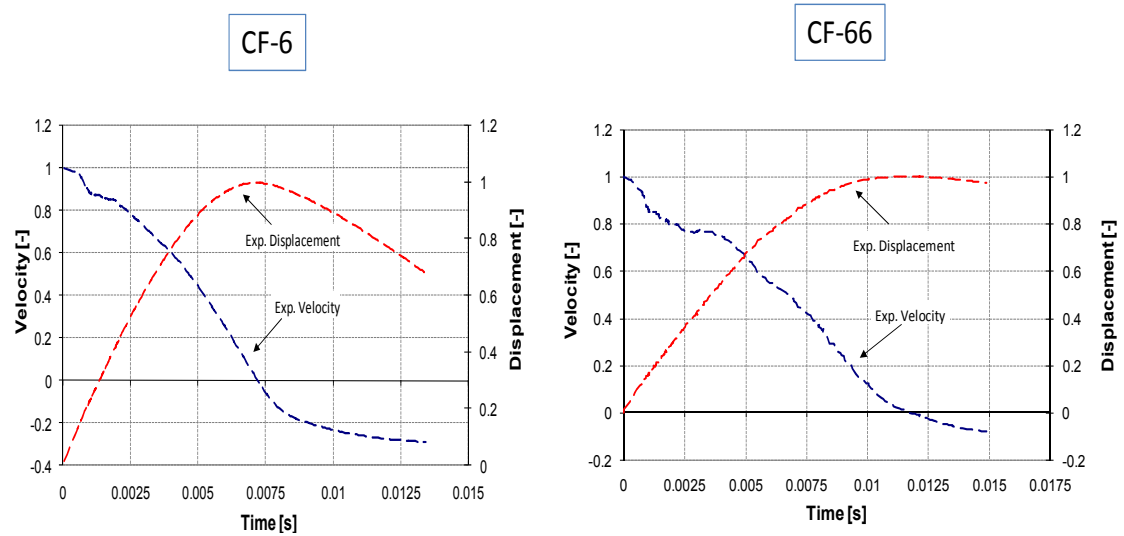

Figure 4: $\quad$ Experimental displacement and velocity of CF6 and CF66.

In this analysis, we did not consider the effect of strain rate on the yield strength. Therefore we assume that the relevant parameters for the phenomenon under study are $m=9$. Applying the Buckingham Pi Theorem, we can determine the dimensionless $\pi_{\mathrm{i}}$ groups. The Buckingham Pi Theorem states that the $\mathrm{m}=9$ relevant dimensional variables can be grouped into $m-n=9-3=6$ dimensionless groups, $\pi_{I}$ [where $n=3$ are the primary dimensions :L(Length), M(Mass) and $\mathrm{T}($ Time $)]$. In this manner the previous function can be expressed as: $\phi\left(\pi_{1}, \pi_{2}, \pi_{3}, \pi_{4}, \pi_{5}, \pi_{6}\right)=0$. There are infinite combinations of the 6 independents dimensionless groups. Table 2 shows the 6 dimensionless groups. It is possible to note that the sixth group can't be constant because the acceleration of gravity is a constant. That means the drop tests are afflicted by a scale effect. Therefore, in the following discussion, the sixth group will not consider. The purpose of the similitude analysis is to evaluate the error introduced by this scale effect. Table 3 
illustrates the values of the dimensionless groups calculated by means of experimental data.

The $11 \%$ of deviation between the two scale models may be representative of the tolerance grade achievable by the manufacturing process of the external shielding of packages. The deviations of the other dimensionless groups are lower than $10 \%$. The results shown in Table 3 could demonstrate also that both the reduced scale models (1:4 and 1:2.5) are able to predict the behaviour of the prototype with an acceptable accuracy.

In order to assess the previous assumption, numerical simulations of the shock absorber deformation were performed by means of a FEM computer code.

Table 2: Dimensionless groups.

\begin{tabular}{|c|c|}
\hline $\mathbf{N}^{\circ}$ & Dimensionless groups \\
\hline $\mathbf{1}$ & $\pi_{1}=\frac{\Delta Z}{Z_{0}}$ \\
\hline $\mathbf{2}$ & $\pi_{2}=\frac{s}{Z_{0}}$ \\
\hline $\mathbf{3}$ & $\pi_{3}=\frac{a \cdot m}{\sigma_{y} \cdot s^{2}}$ \\
\hline $\mathbf{4}$ & $\pi_{4}=t \cdot \sqrt{\frac{\sigma_{y} \cdot s}{m}}$ \\
\hline $\mathbf{5}$ & $\pi_{5}=\frac{\Delta Z \cdot \sigma_{y} \cdot s^{2}}{m \cdot g \cdot H}$ \\
\hline $\mathbf{6}$ & $\pi_{6}=\frac{a}{g}$ \\
\hline
\end{tabular}

Table 3: Comparison between experimental dimensionless groups of the CF-6 and CF-66 scale models.

\begin{tabular}{|c|c|c|c|}
\hline Dimensionless groups & CF6 & CF66 & Deviation (\%) \\
\hline 1 & 0.106 & 0.095 & 11.220 \\
\hline 2 & 0.170 & 0.170 & 0.136 \\
\hline 3 & 5.850 & 5.774 & 1.324 \\
\hline 4 & 0.115 & 0.117 & 1.112 \\
\hline 5 & 0.014 & 0.013 & 8.909 \\
\hline
\end{tabular}

\section{Numerical simulations of the dynamic deformation of the packages}

As mentioned before, the vermiculite-concrete mixture used in the CF packages is different from the mixture used in [1] from the composition point of view. 
Thus, the aim of numerical simulations is to evaluate the right parameters to simulate the drop test of $\mathrm{CF}$ packages starting from the mechanical characteristics of the vermiculite-concrete mixture seen in [1]. The mixture was implemented as a isotropic-homogenous material with elasto-plastic characteristics. The plastic phase is non linear and it was obtained from fig 1 . Also, the Young modulus and the yield strength were obtained from fig 1. The strain rate effect on the yield strength has been considered using the CowperSymonds relations:

$$
\sigma_{y}=\sigma_{y o}\left[1+\left(\frac{\dot{\varepsilon}}{D}\right)^{1 / n}\right]
$$

where $D=47.5 \mathrm{~s}^{-1}$ and $\mathrm{n}=4$ are the values of the material constants deduced by considering the difference of the yield strength between the dynamic and static behaviour of the mixture (see fig 1). In fig. 5 is shown the model mesh utilized for numerical analysis and the load condition. In this model the closing device is not described. This mesh was obtained by means of several simulations to have mesh independent results. Table 4 shows the finally numerical values used in the analysis to simulate the vertical drop test of CF package. We can point out that the yield strength used in the numerical simulation is smaller than the yield strength used in [1]. Figure 6 shows the comparison between the numerical and experimental results on the CF-6 Package in terms of accelerations and displacements. Figure 7 shows the comparison between the numerical and experimental results on the CF-66 Package in terms of accelerations and displacements. The numerical slope behavior of both packages is quite similar to experimental ones in terms of transient time and maximum acceleration. Tables 5 and 6 show the deviation from numerical and experimental results on the $\mathrm{CF}$ packages by means of dimensional analysis.

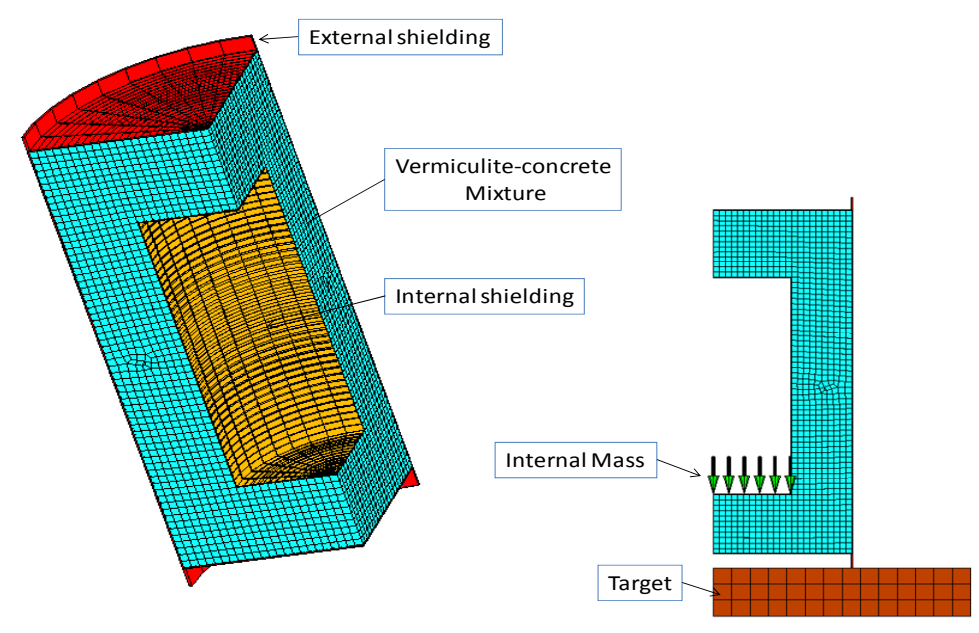

Figure 5: Mesh and load conditions of CF6 packages used in the F.E. analysis. 
Table 4: $\quad$ Model parameters used in the FE analysis.

\begin{tabular}{|c|c|c|c|c|c|c|}
\hline \multicolumn{7}{|c|}{ Absorber Data Input } \\
\hline \multirow{2}{*}{$\begin{array}{c}\text { Young's } \\
\text { Modulus (Mpa) }\end{array}$} & \multirow{2}{*}{$\begin{array}{c}\text { Poisson's } \\
\text { Ratio }\end{array}$} & \multirow{2}{*}{$\begin{array}{c}\text { Mass Density } \\
\left(\mathrm{Kg} / \mathrm{m}^{3}\right)\end{array}$} & \multirow{2}{*}{$\begin{array}{l}\text { Initial Yield } \\
\text { Stress (Mpa) }\end{array}$} & \multicolumn{2}{|c|}{ Cowper-Symonds } & \multirow{2}{*}{$\begin{array}{l}\text { Damping stiffness } \\
\text { matrix multiplier }\end{array}$} \\
\hline & & & & Coefficient $D$ & Exponent $\mathrm{n}^{-1}$ & \\
\hline 144 & 0.05 & 600 & 0.284 & 47.5 & 4 & $1 \mathrm{E}-5$ \\
\hline
\end{tabular}

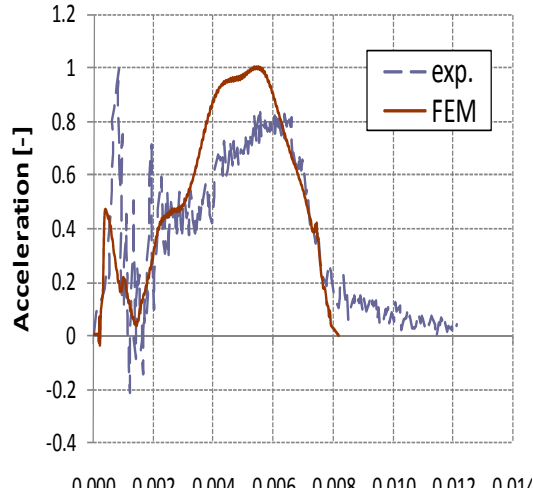

Time $[s]$

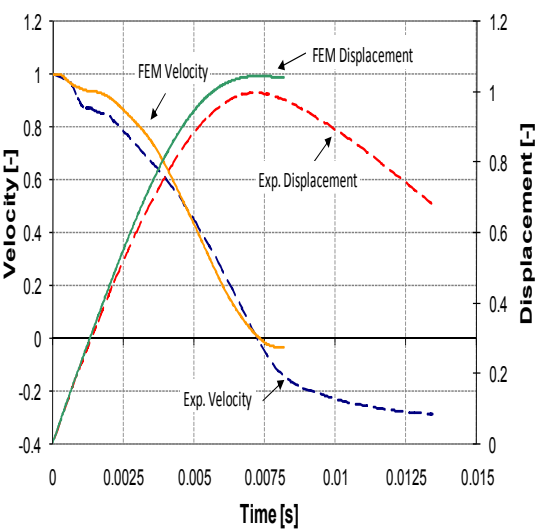

Figure 6: Comparison between experimental and numerical results of CF6.
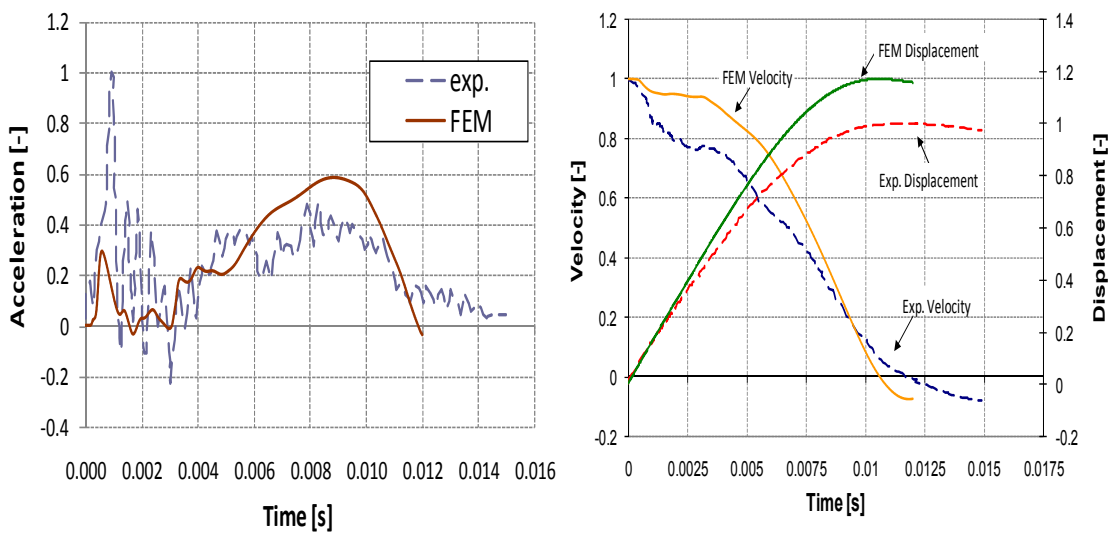

Figure 7: Comparison between experimental and numerical results of CF66.

The maximum deviation is on the third group. This deviation is due at greater stiffness of numerical models in comparison with experimental ones. In fact, the numerical isotropic-homogenous model can't simulate the void inside the mixture (due to air inserted) that, collapsing, reduces the mixture stiffness. But from the design point of view, this effect is precautionary because it overestimates the acceleration on the internal waste cask. Finally, the numerical simulation on the 1:1 scale model of CF-6 (called CFR) was performed. Figure 8 and Table 7 show the results and the deviation between the three numerical 
models. We can point out the comparison between CF-66 and CFR gives good results with a maximum deviation of $15.42 \%$ else the comparison between CF-6 and CFR gives a maximum deviation of $4.93 \%$. In conclusion, the scale effect on the 1:2,5 scale model (CF-66) gives negligible error and so this scale model is a good model to understand the behavior of a real prototype of same geometric and material characteristics.

Table 5: Comparison between experimental and numerical dimensionless groups of CF-6 scale models.

\begin{tabular}{|c|c|c|c|}
\hline $\begin{array}{c}\text { Dimensionless } \\
\text { groups }\end{array}$ & $\begin{array}{c}\text { Experimental } \\
\text { data }\end{array}$ & Numerical data & Deviation (\%) \\
\hline 1 & 0.106 & 0.109 & 3.39 \\
\hline 2 & 0.170 & 0.170 & 0.00 \\
\hline 3 & 5.850 & 7.923 & 26.16 \\
\hline 4 & 0.115 & 0.115 & 0.00 \\
\hline 5 & 0.014 & 0.015 & 3.39 \\
\hline
\end{tabular}

Table 6: Comparison between experimental and numerical dimensionless groups of CF-66 scale models.

\begin{tabular}{|c|c|c|c|}
\hline $\begin{array}{c}\text { Dimensionless } \\
\text { groups }\end{array}$ & $\begin{array}{c}\text { Experimental } \\
\text { data }\end{array}$ & $\begin{array}{c}\text { Numerical } \\
\text { data }\end{array}$ & Deviation (\%) \\
\hline 1 & 0.094 & 0.110 & 14.74 \\
\hline 2 & 0.170 & 0.170 & 0.00 \\
\hline 3 & 6.423 & 9.382 & 31.54 \\
\hline 4 & 0.107 & 0.107 & 0.00 \\
\hline 5 & 0.013 & 0.015 & 14.74 \\
\hline
\end{tabular}
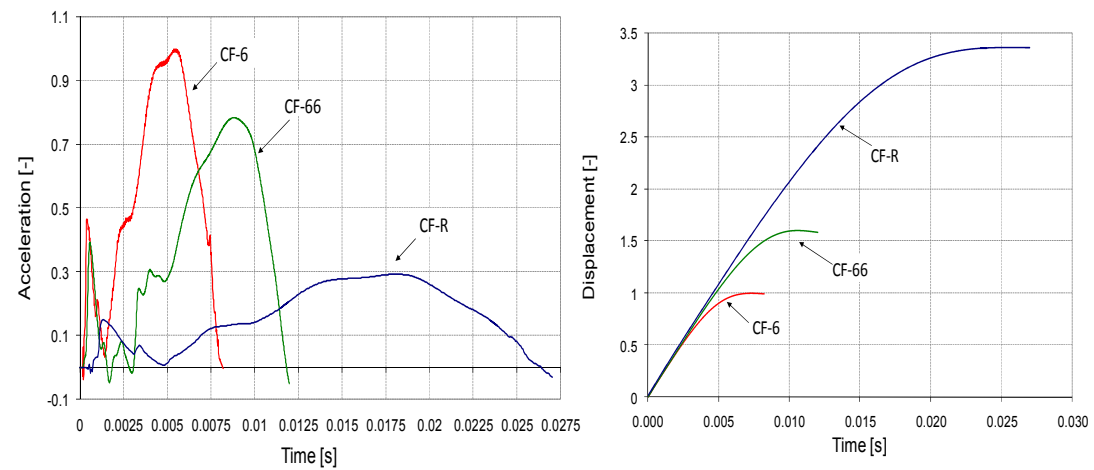

Figure 8: Comparison between the numerical models used in the analysis: CF6, CF66 and CFR. 
Table 7: Deviation between dimensionless groups obtained by F.E. analysis of CF6, CF66 and CFR.

\begin{tabular}{|c|c|c|c|}
\hline $\begin{array}{c}\text { Dimensionless } \\
\text { groups }\end{array}$ & $\begin{array}{c}\text { Deviation (\%) } \\
\text { CF6-CF66 }\end{array}$ & $\begin{array}{c}\text { Deviation (\%) } \\
\text { CF66-CFR }\end{array}$ & $\begin{array}{c}\text { Deviation (\%) } \\
\text { CF6-CFR }\end{array}$ \\
\hline 1 & 0.63 & 3.26 & 2.61 \\
\hline 2 & 0.14 & 0.14 & 0.00 \\
\hline 3 & 15.55 & 0.27 & 15.32 \\
\hline 4 & 10.00 & 4.93 & 15.42 \\
\hline 5 & 2.70 & 2.98 & 0.20 \\
\hline
\end{tabular}

\section{Conclusions}

This paper illustrates the experimental results and the numerical simulations of the $9 \mathrm{~m}$ vertical free drop tests for a nuclear waste package type $\mathrm{B}(\mathrm{U})$. The aim of this work was to develop a numerical model to simulate the vermiculiteconcrete mixture used in packages as a shock absorber. The experimental tests were performed on 1:4 and 1:2.5 scale models called respectively CF-6 and CF-66. The results were extrapolated to the prototype on the basis of scale laws determined by means of a similitude analysis. The numerical simulations were started considering the mechanical characteristics of vermiculite-concrete mixture found in the literature and performed to simulate the results of experimental tests on the packages of different scales (1:1, 1:2.5 and 1:4). The main objective was to verify the accuracy of the numerical model developed and the accuracy of the scale laws found for the different scale models. This analysis allowed, also, one to identify the smallest scale model which can give reliable results in the experimental tests. The 1:2.5 scale model (CF-66) seems suitable to determine the behaviour of the cask in the $9 \mathrm{~m}$ free drop test with a maximum deviation lower than $5 \%$.

\section{References}

[1] C. Covington, Dynamic energy-absorbing characteristics of lightweight vermiculite concrete, Structural Mechanics Research Laboratory of University of Texas, 1961.

[2] P. Citti, G. Forasassi, B. Guerrini, RL 113 (72) Trasporto di materiale radioattivo: attrezzatura di collaudo ed esperienze eseguite su prototipi del contenitore CF6, University of Pisa, 1972.

[3] IAEA, Regulations for the Safe Transport of Radioactive Material (2005 Edition), Safety Standards Series No. TS-R-1, Vienna, 2005.

[4] D. Aquaro, M. DiPrinzio, G. Forasassi, N. Zaccari, "Numerical and experimental analysis of the impact of a nuclear spent fuel cask", 19th International Conference on Structural Mechanics in Reactor Technology SMIRT19), Toronto, 12-17 August 2007, Toronto, Canada. 